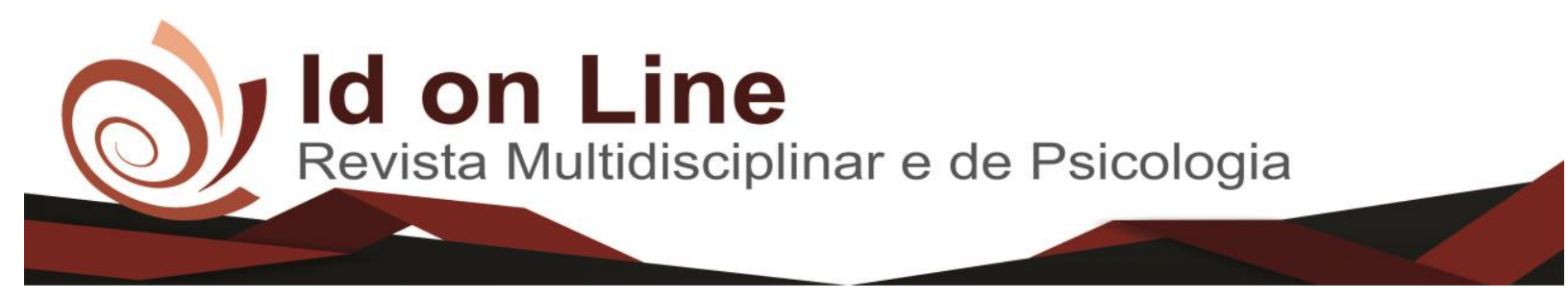

Artigo

\title{
Violência Contra Idosos: \\ Associação Entre o Gênero dos Agressores e o Tipo de Violência
} Adriene Reis Silval, Lucas Silveira Sampaio²; Luciana Araújo dos Reis
Talita Santos Oliveira Sampaio

Resumo: Este estudo tem como objetivo analisar a associação entre o gênero dos agressores dos idosos com o tipo de violência. Trata-se de uma pesquisa quantitativa analítica-descritiva com delineamento transversal, que utilizou dados da pesquisa "Violência Contra Idosos: Perfil das Violências Segundo Registro das Instâncias de Referência". Foram utilizadas 55 notificações de violência contra idosos registradas no SINAN, entre 2012 a 2015 no município de Vitória da Conquista - BA. Segundo os resultados, os cônjuges são os principais agressores de idosos (27,3\%), sendo que o sexo masculino foi o mais prevalente nas agressões $(74,5 \%)$. O tipo de violência mais relatado foi a psicológica $(83,6 \%)$, seguida da física $(49,1 \%)$. Observou-se que a variável sexo está associada com todas as violências (psicológica, sexual, financeira, física e negligência). Diante disso, salienta-se a necessidade de elaboração de ações que visem à prevenção desse abuso e melhorias na assistência tanto a vítima como o agressor.

Palavras-chave: Envelhecimento Populacional. Maus-tratos ao Idoso. Idoso.

\section{Violence Against Elderly: Association Between the Gender of Aggressors and the Type of Violence}

Abstract: This study aims to analyze the association between the gender of the aggressors of the elderly with the type of violence. This is a quantitative analytical-descriptive research with a cross-sectional design, which used data from the research "Violence Against Elderly: Profile of Violence According to Record of Reference Instances". Fifty-five reports of violence against the elderly registered in SINAN between 2012 and 2015 in Vitória da Conquista - BA were used. According to the results, the spouses are the main aggressors of the elderly (27.3\%), and the male sex was the most prevalent in the aggressions (74.5\%). The most reported type of violence was psychological (83.6\%), followed by physical (49.1\%). It was observed that the gender variable is associated with all violence (psychological, sexual, financial, physical and neglect). Therefore, it is necessary to elaborate actions aimed at the prevention of this abuse and improvements in the care of both the victim and the aggressor.

Keywords: Population Aging. Elder abuse. Elderly.

\footnotetext{
${ }^{1}$ Discente do curso de Fisioterapia na Faculdade Independente do Nordeste (FAINOR). Contato: adriene_drika22@hotmail.com

${ }^{2}$ Docente do curso de Fisioterapia na Faculdade Independente do Nordeste ( FAINOR). Mestre em Ciências da Saúde pela Universidade Estadual do Sudoeste da Bahia (UESB). Contato: lucasosampaio@ hotmail.com

${ }^{3}$ Docente da Faculdade Independente do Nordeste (FAINOR). Doutora em Ciências da Saúde pela Universidade Federal do Rio Grande do Norte e Pós-Doutorado em Saúde Coletiva pelo Instituto de Saúde Coletiva da Universidade Federal da Bahia (UFBA). Contato: lucianareisfainor@gmail.com

${ }^{4}$ Docente do curso de Fisioterapia na Faculdade Independente do Nordeste (FAINOR). Mestre em Ciências da Saúde pela Universidade Estadual do Sudoeste da Bahia. Contato: talitafisio@gmail.com
} 


\section{Introdução}

No Brasil são consideradas pessoas idosas, indivíduos com mais de 60 anos de idade de acordo a Política Nacional do Idoso. A população idosa é a que mais cresce no Brasil, sendo consequência da melhoria das condições de saúde, diminuição das taxas de natalidade e o aumento da renda. O envelhecimento populacional é um fenômeno que repercute tanto nos aspectos sociais, como econômicos e culturais, afetando diretamente a família, o estado e sociedade. Essas mudanças demográficas ocorreram de forma rápida no país, onde no ano de 2011 a população de idosos chegou a 23,5 milhões, o que estava previsto somente para 2020 (INSTITUTO BRASILEIRO DE GEOGRAFIA E ESTATÍSTICA- IBGE, 2010; VERAS, 2012).

O processo de envelhecimento gera falsas ideias de que a velhice esteja associada à inutilidade, o que repercute em inúmeros desafios para essa população. Dentre esses, destacase o preconceito e a discriminação que aumenta o risco da violência (BRASIL, 2014). A violência contra idosos ocorre tanto em países em desenvolvimento como em países desenvolvidos. Consiste em um problema social, político e de saúde pública, pois afeta a integridade corporal, psicológica e emocional da vítima (MENDONÇA; REIS, 2016).

São considerados maus-tratos contra idosos toda ação ou omissão em lugares públicos ou privados que lhe cause complicações físicas, psicológicas ou até a morte (BRASIL, 2003). São considerados sete tipos de violência: abuso físico, psicológico, sexual, abandono, negligência, financeiro e autonegligência (MIZIARA et al., 2015). As agressões trazem consequências irreversíveis ao idoso como o isolamento, alterações emocionais (depressão, tentativas de suicídio e perda da identidade), traumas físicos, sentimento de culpa, negação e muitas vezes o risco do óbito (BARCELOS; MADUREIRA, 2013).

Mesmo com a alta prevalência de violência há um número reduzido de denúncias por parte do idoso, pois muitos possuem a dificuldade de perceber que está sofrendo violência, além do medo e da insegurança de denunciar seus agressores, que geralmente são os próprios familiares, o que dificulta o reconhecimento desses casos e suas notificações (OLIVEIRA et al., 2012).

São vários os fatores que podem levar a ocorrência das violências contra o idoso, como por exemplo, a dependência do idoso por cuidados devido à diminuição de sua capacidade funcional e cognitiva. Esse cuidado pode gerar uma sobrecarga aos seus cuidadores ou 
familiares, gerando um possível conflito (PAIVA; TAVARES, 2015). Além desse fator, podese destacar o empobrecimento da população, a nova formação familiar e a moradia conjunta de idosos com seus familiares (OLIVEIRA; DIAS; REIS, 2015).

A família em geral é o maior violador dos direitos dos idosos, sendo o principal agressor e sua residência é o lugar de maior ocorrência (OLIVEIRA et al., 2012; CACHINA; PAIVA; TORRES, 2016). Nem sempre o convívio de membros mais velhos com a família vai ser um fator positivo para o envelhecimento saudável, uma vez que a dependência do idoso pode sobrecarregar a família e por outras vezes, o convívio intergeracional pode favorecer a diferenças de ideias (ABATH; LEAL; FILHO, 2012).

A violência contra o idoso é assunto que precisa ser constantemente abordado, sendo uma violação grave dos direitos dos idosos e um sério problema de saúde pública. Tornam-se necessários estudos que busquem aprofundar sobre tal temática, uma vez que ainda existe muita carência de informações sobre agressores, fatores que provocam os tipos de violência e suas repercussões. Isso possibilitará a criação de medidas preventivas voltadas ao combate da violência e a um maior conhecimento de toda sociedade e Estado sobre o assunto. Nesse sentido, este estudo tem por objetivo analisar a associação entre o gênero dos agressores dos idosos com o tipo de violência.

\section{Métodos}

Trata-se de um estudo quantitativo analítico-descritivo e com delineamento transversal. Este estudo é um recorte do projeto intitulado "Violência contra idosos: perfil das violências segundo registro nas instâncias de referência" que utilizou dados secundários dos boletins de ocorrência e bancos de dados dos casos de violência(s) (negligência, abandono, violência física e sexual e outras violências).

A pesquisa foi realizada no município de Vitória da Conquista - BA, localizada na região sudoeste do Estado. Os dados foram obtidos através do Sistema Nacional de Agravos de Notificações-SINAN e do Sistema de Vigilância de Violências e Acidentes-VIVA, fornecidos pela Vigilância Epidemiológica no período entre os anos de 2012 a 2015, totalizando 55 notificações de violências. 
Para a coleta dos dados, a princípio, foi estabelecido contato com a secretária municipal de saúde/vigilância epidemiológica, onde foi solicitada a permissão para coleta, por meio das fichas VIVA (notificaçãol investigação de violência e acidentes).

Depois da submissão e aprovação pelo comitê de ética em pesquisa da Faculdade Independente do Nordeste - FAINOR foi feito novo contato com as instituições, daí iniciou-se a coleta dos dados, realizada por uma equipe devidamente treinada que atenderam aos aspectos básicos do procedimento, levando em conta os aspectos éticos e sigilosos da consulta nos bancos de dados e boletins. É importante evidenciar que esse processo não afetou a rotina de trabalho, cumprindo rigorosamente o cronograma definido com o núcleo de prevenção.

A análise dos dados foi desenvolvida através de estatística descritiva com distribuição das frequências absolutas, médias e desvio padrão. O teste Qui-quadrado realizou a relação entre as variáveis. O nível de significância adotado foi de $5 \%(\alpha=0,05)$ e a tabulação dos dados foi executada no programa Excel 2013. Além disso, a análise estatística dos dados foi produzida pelo programa de The StatisticalPackage for Social Sciences para Windows (SPSS 21.0, 2013, SPSS, Inc, Chicago, IL).

Essa pesquisa obedeceu às normas éticas exigidas pela Resolução n ${ }^{\circ}$ 466/2012 (Conselho Nacional de Saúde). O protocolo foi submetido ao Comitê de Ética em Pesquisa com Seres Humanos da Faculdade Independente do Nordeste, desse modo à coleta foi iniciada apenas após aprovação e autorização do CEP- FAINOR. Foi solicitada a dispensa de Termo de Consentimento Livre e Esclarecido-TCLE, pois os dados foram coletados de fonte secundária.

\section{Resultados}

Na tabela 1 observa-se as características dos agressores de idosos analisados no estudo. O grau de parentesco que mais está envolvido nas agressões contra os idosos são os cônjuges $(27,3 \%)$. Observou-se também que a maioria dos agressores são do sexo masculino, sendo $(74,5 \%)$. 
Tabela 1. Análise descritiva dos agressores de idosos. Vitória da Conquista - BA, 2017.

\begin{tabular}{lccc}
\hline Variáveis & \% resposta & $\mathrm{N}$ & $\%$ \\
\hline Vínculo / Grau de parentesco & 90,0 & & \\
$\quad$ Cônjuge & & 15 & 27,3 \\
Ex-cônjuge & & 10 & 18,2 \\
Ex-namorado & 1 & 1,8 \\
Filho (a) & & 9 & 16,4 \\
Irmão (a) & 2 & 3,6 \\
Desconhecidos & & 1 & 1,8 \\
Policial / Agente da lei & 1 & 1,8 \\
Própria pessoa & 1 & 1,8 \\
Outros & 92,7 & 17 & 30,9 \\
Sexo do provável agressor & & 41 & 74,5 \\
Masculino & & 10 & 18,2 \\
Feminino & & 2 & 3,6 \\
Ambos os sexos & & & \\
\end{tabular}

Fonte: Dados da pesquisa.

Com relação à Tabela 2 abaixo, nota-se que esta apresenta os tipos de violência contra os idosos, destacando que a violência mais relatada foi a do tipo psicológica $(83,6 \%)$, seguida da violência tipo física $(49,1 \%)$.

Tabela 2. Análise descritiva dos tipos de violência. Vitória da Conquista - BA, Brasil, 2017.

\begin{tabular}{lccc}
\hline Variáveis & \% resposta & $\mathrm{N}$ & $\%$ \\
\hline Tipo de violência & 90,9 & & \\
Física & & 27 & 49,1 \\
Psicológica & & 46 & 83,6 \\
Sexual & & 11 & 20 \\
Financeira & & 23 & 41,8 \\
Negligência & & 1 & 1,8 \\
Outros & & 3 & 5,5
\end{tabular}

Fonte: Dados da pesquisa.

Em relação às características das violências cometidas, constata-se uma maior prevalência de agressões contra idosos no âmbito urbano $(81,8 \%)$, sendo as agressões realizadas mais de uma vez $(85,5 \%)$ e praticadas por um agressor $(83,6 \%)$. Observou-se também que a maioria das violências foram efetuadas por meio de ameaças $(36,4 \%)$, seguidas por força corporal e espancamento $(32,7 \%)$ (tabela 3$)$. 
Tabela 3. Caracterização das violências contra idosos. Vitória da Conquista/Ba, 2016.

\begin{tabular}{lccc}
\hline Variáveis & \% resposta & N & \% \\
\hline Zona de ocorrência & 100 & & \\
Urbana & & 45 & 81,8 \\
Rural & & 8 & 14,5 \\
Periurbana & 100 & 2 & 3,6 \\
Ocorreu outras vezes & & & \\
$\quad$ Sim & & 47 & 85,5 \\
Não & 96,4 & 7 & 12,7 \\
Número de envolvidos & & 46 & 83,6 \\
Um & & 7 & 12,7 \\
Dois ou mais & 100 & 3 & 5,7 \\
Lesão auto-provocada & & 50 & 94,3 \\
Sim & & 18 & 32,7 \\
Não & 32,7 & 4 & 7,3 \\
Meios de agressão* & 7,3 & 7 & 12,7 \\
$\quad$ Força corporal/Espancamento & 12,7 & 3 & 5,5 \\
Enforcamento & 5,5 & 2 & 3,6 \\
Objeto contundente & 3,6 & 20 & 56,4 \\
Objeto perfuro cortante & 36,4 & 3 & \\
Arma de fogo & 5,5 & & \\
Ameaça & & & \\
Outras & & & \\
\hline
\end{tabular}

Fonte: Dados da pesquisa.

Analisando-se a associação entre o gênero dos agressores dos idosos e os tipos de violência sofrida, observou-se que a variável sexo está associada com todas as violências (psicológica, sexual, financeira, física e negligência) (tabela 4).

Tabela 04. Associação entre o gênero dos agressores e o tipo de violência contra idosos. Vitória da Conquista, Brasil, 2016.

\begin{tabular}{lc}
\hline Variáveis & Qui-Quadrado (p-valor) \\
\hline Violência Física x Sexo & 0,000 \\
Violência Psicológica x Sexo & 0,002 \\
Violência Negligência x Sexo & 0,000 \\
Violência Financeira x Sexo & 0,000 \\
Violência Sexual x Sexo & 0,000 \\
\hline
\end{tabular}

Fonte: Dados da pesquisa.

\section{Discussão}

Algumas teorias tentam explicar porque a violência contra o idoso é tão prevalente, daí surge algumas hipóteses, como a vulnerabilidade física e mental dessas vítimas, os transtornos 
emocionais do agressor e o estresse do cuidador (MIZIARA et al., 2015). Os abusadores de idosos na maioria das vezes conviveram e foram educados em um ambiente violento ou foram vítimas de maus-tratos na infância, e acabam refletindo essas ações nos seus relacionamentos familiares. Se o idoso no passado foi o agressor, a chance de ser agredido quando mais velho é aumentada como forma de vingança ou retaliação (SILVA; DIAS, 2016).

Diante dos resultados do presente estudo, nota-se que as agressões contra idosos são realizadas em sua maioria pelo cônjuge com $27,3 \%$ da população estudada. Segundo o estudo de Gil et al. (2015) a maioria dos violentadores de idosos pertencem a família da vítima sendo os cônjuges (atuais ou não), filhos ou filhas os principais agressores. No estudo de Irigaray et al. (2016) o cônjuge ou o companheiro da vítima foi o segundo principal agressor com 22,7\%, porém houve predominância dos filhos como principais violentadores com o percentual de $66,4 \%$.

De acordo com o estudo, no que se refere ao sexo do agressor à maioria dos agressores de idosos são do sexo masculino com 74,5\%. Esse dado corrobora aos achados de Aguiar et al. (2015) que em relação ao sexo do agressor também houve maior prevalência do sexo masculino com $74,1 \%$.

Ressalta-se que o estudo principal que deu origem a este estudo, verificou que $100 \%$ dos idosos violentados eram do sexo feminino. Observa-se neste sentido, que a maioria dos agressores serem do sexo masculino e cônjuges, pode estar relacionado a violência de gênero, onde as mulheres são as principais vítimas de seus parceiros conjugais. Os homens são os maiores agressores, devido à cultura de superioridade masculina, que supervaloriza o homem e considera a mulher como o sexo frágil e dependente. Com isso, devido a sua fragilidade, as mulheres se tornam submissas a seus parceiros, onde a violência começa muito cedo na vida do casal e se estende na idade avançada (MASCARENHAS et al., 2012). A fragilidade feminina é muito mais evidente na velhice, já que o processo de envelhecimento associado a alguma doença crônica tornam-nas mais incapacitadas funcionalmente e mais vulneráveis a violência (BOLSONI et al., 2016).

Em relação aos tipos de violência praticada pelos agressores, nesse estudo houve uma maior prevalência de violência psicológica com um percentual de 83,6\% dos dados, seguido de violência física com 49,1\%. No estudo de Oliveira et al. (2012) a violência psicológica também apresentou maior número de ocorrências $(55,24 \%)$ seguido da física $(41,73 \%)$. Entretanto, no estudo de Paraíba e Silva (2015) a violência física foi à agressão mais prevalente com 44,96\%. 
O abuso psicológico está associado a ameaças do agressor, uso de autoritarismo e ofensas para que o idoso se mantenha submisso a ele. Esse ato acaba desqualificando o idoso, fazendo com que ele se sinta ameaçado e envergonhado. Uma possibilidade para explicação da ocorrência de agressões psicológicas seria as discussões familiares e de algum tipo de negociações financeiras que geralmente são feitas de forma verbal (IRIGARAY et al., 2016). Muitas vezes a identificação da violência psicológica se torna difícil, uma vez que não se trata apenas de violência física, perceptível pelas lesões corporais, mas também de danos morais, psicológicos e sociais (OLIVEIRA; TRIGUEIRO, 2013).

Segundo Paiva e Tavares (2015) a violência física está sempre acompanhada da violência psicológica, criando um ciclo de violência, pois antes de agredir fisicamente, o agressor ameaça, e essa agressão é considerada como violência psicológica. De acordo com Ramos (2011) e Abath, Leal e Filho (2012) a maior parte das agressões físicas são efetuadas por homens com grau de parentesco próximo da vítima, como cônjuges, filhos e genros. As violações psicológicas em alguns estudos são mais exercidas por mulheres, já que elas são as principais responsáveis pelo cuidado ao idoso.

Em relação ao local de ocorrências das agressões, neste estudo constata-se uma maior prevalência de agressões contra idosos no âmbito urbano (81,8\%). O isolamento e a falta de apoio social nas zonas rurais pode ser um fator determinante na ausência de denúncias sobre violências nesses locais, fazendo com que as denúncias de violência urbana se sobressaiam. Percebe-se que os órgãos de proteção e fiscalização dos direitos dos idosos ainda encontram dificuldades na assistência e prestação de atendimento ao idoso, devido a carência de profissionais, de transportes e instrumentos de trabalho para as visitas domiciliares, sobretudo nas zonas rurais. Esses fatores acabam elevando o número de denúncias de violência urbana, pelo maior contato que o idoso morador da zona urbana possui com as instituições de fiscalização (CACHINA; PAIVA; TORRES, 2016).

Com relação à reincidência de violência nesse estudo, constata-se que em $85,5 \%$ dos casos ocorreram mais de uma vez. Aumenta-se a possibilidade de ocorrências de um novo episódio violento quando a vítima se sente frágil e submissa ao agressor, isso faz com que as agressões se tornem um vício e esses atos são repetidos diversas vezes (ZANCAN; WASSERMANN; LIMA, 2013). De acordo com Paraíba e Silva (2015), quando ocorre a denúncia da violência doméstica, já ocorreram vários episódios anteriores e tendem a ser repetidos até que aconteça uma mudança no ambiente. Nesse sentido, é importante detectar os 
casos de violência, notificá-los e oferecer a assistência necessária as vítimas, isso evita que essas agressões continuem se perpetuando no cotidiano do idoso (GIL et al., 2015).

Sobre os meios de agressão, nota-se que as ameaças apresentaram a maior porcentagem, com 36,4\%, o que se relaciona com a maior prevalência de maus-tratos psicológicos. Já as lesões físicas por espancamento/uso de força corporal ficaram em segundo lugar com o percentual de 32,7\%. Contrário aos dados desse estudo, a pesquisa realizada por Oliveira et al. (2012) observou que os tipos de maus-tratos mais frequentes foram as lesões corporais com $32,54 \%$, seguido das ameaças com um percentual de 30,78\%. Geralmente o agressor ameaça suas vítimas antes de agredir fisicamente, com o objetivo de intimidá-las. Tal situação demonstra que as ameaças não podem ser negligenciadas, pois já são indícios de agressão física futura.

Os resultados do estudo em questão encontrou uma associação entre o sexo dos agressores de idosos e o tipo de violência sofrida. Foi possível observar que a variável sexo está associada com todas as violências (psicológica, sexual, financeira, física e negligência). No estudo de Abath, Leal e Filho (2012) observou-se uma ligação estatisticamente significante entre os maus-tratos domésticos e o sexo do violador.

No presente estudo, o sexo masculino foi o mais prevalente em relação ao agressor, estando diretamente relacionado com as violências. O comportamento violento dos homens muitas vezes está associado à ideia de poder, de força e autoridade imposta pela sociedade, o que faz com que o sexo masculino esteja mais envolvido nos episódios violentos. $\mathrm{O}$ abuso de álcool e drogas também está mais associado a indivíduos do sexo masculino, o que acaba propiciando os maus-tratos no seio familiar (SANTANA; VASCONCELOS; COUTINHO, 2016).

A violência de gênero, mais precisamente a violência contra o sexo feminino, está diretamente ligada ao pensamento estereotipado e preconceituoso de uma sociedade machista que considera a mulher como um ser inferior. $\mathrm{O}$ fato da maioria das vítimas de violências serem do sexo feminino se reflete nos dados populacionais, já que existem mais mulheres na terceira idade do que homens, além disso, as idosas têm mais iniciativa que os idosos em denunciar, pois devido à ideia de superioridade masculina o homem se sente envergonhado em reconhecer que esta sofrendo agressões (BOLSONI et al., 2016).

Nessa pesquisa foi possível observar um grande número de subnotificações dos casos de violência. Segundo Paraíba e Silva (2015) há um número reduzido de denúncias por parte do idoso, além disso, as subnotificações também decorrem do despreparo dos profissionais de 
saúde de reconhecer e investigar possíveis casos de violências, da dificuldade no preenchimento da ficha e da fragilidade nas redes de apoio, que dificultam as notificações.

\section{Considerações Finais}

O estudo em questão abordou um problema bastante prevalente na sociedade, que é a violência contra idosos, demostrando que a maioria dos agressores são os cônjuges e do sexo masculino. Os achados evidenciam que em relação aos tipos de violências praticada pelos violentadores houve maior prevalência de violência psicológica, seguida da física. Constatouse um maior número de agressões na zona urbana, onde a maioria dos casos foram reincidentes. Em relação aos meios de agressões, a ameaça obteve maior frequência nos casos, seguida de agressões físicas por espancamento e uso de força corporal. Neste estudo houve uma associação entre o sexo dos agressores de idosos, com todos os tipos de violência.

Nesse sentido, os dados desse estudo, ressaltam a real dimensão da violência em uma sociedade, servindo de alicerce para a criação de políticas públicas mais atuais, ações de saúde para essa população de risco, e um maior planejamento da assistência voltada para os cuidadores e familiares de pessoas na terceira idade. Além disso, esse estudo tem a finalidade de alertar e informar a sociedade sobre a problemática da violência podendo-se evitar possíveis subnotificações.

\section{Referências}

ABATH, M.B.; LEAL, M.C.C.; FILHO, D.A.M. Fatores associados à violência doméstica contra a pessoa idosa. Revista Brasileira de Geriatria e Gerontologia, Rio de Janeiro, v.15, n. 2, p.305-314, jan./dez. 2012.

AGUIAR, M.P.C. et al. Violência contra idosos: descrição de casos no Município de Aracaju, Sergipe, Brasil. Escola Anna Nery Revista de Enfermagem. v.19,n.2, p.343-349, abr./jun. 2015.

BRASIL. Manual de enfrentamento à violência contra a pessoa idosa. É possível prevenir. É necessário superar. Secretária de Direitos Humanos da Presidência da República; Texto de Maria Cecília de Souza Minayo. Brasília,DF, p.90, 2014. 
BRASIL. Ministério da Saúde. Redes Estaduais de Atenção à Saúde do Idoso: Guia Operacional e Portarias Relacionadas. Brasília: Ministério da Saúde, 2002.

BARCELOS, E. M..; MADUREIRA, M. D. S. Violência contra o idoso. In F. Chaimowicz (Ed.), Saúde do idoso, Belo Horizonte: UFMG, p.132-141, 2013.

BRASIL. Estatuto do Idoso. Lei No 10.741 , de $1^{\circ}$ de outubro de 2003. Diário Oficial da União, Brasília, n. 192, 3 out. 2003.

BOLSONI, C.C. et al. Prevalência de violência contra idosos e fatores associados, estudo de base populacional em Florianópolis, SC. Rev. Bras. Geriatr. Gerontol, Rio de Janeiro, v. 19, n. 4, p. 671-682, maio/jul. 2016.

CACHINA, A. M. P.; PAIVA, I.L.; TORRES, T.L. Violência intrafamiliar contra idosos: revisão sistemática. Universidade Federal do Rio Grande do Norte, Brasil, v. 22, n. 2, p. 185 196, mar./set. 2016.

GIL, A.P. et al. Estudo sobre pessoas idosas vítimas de violência em Portugal: sociografia da ocorrência. Cad. Saúde Pública, Rio de Janeiro, v.31, n.6, p.1234-1246, jun. 2015.

IBGE. Instituto Brasileiro de Geografia e Estatística. Disponível em: <http://www.ibge.gov.br/home/estatistica/populacao>. Acesso em abril de 2017.

IRIGARAY, T. Q. et al. Maus-tratos contra idosos em Porto Alegre, Rio Grande do Sul: um estudo documental. Estudos de Psicologia, Campinas, v. 33, n.3, p. 543-551, jul./set. 2016.

MENDOÇA, M.; REIS, L.A. Caracterização da violência contra mulheres idosas no município de Vitória da Conquista/BA. Revista Enfermagem Contemporânea, Vitória da Conquista, v.4, n.2, p.129-136, jul./dez. 2016.

MIZIARA, C.S.M.G. et al. Vítima silenciosa: violência doméstica contra o idoso no Brasil. Saúde Ética \& Justiça, São Paulo, v. 20, n.1, p.1-8, mai.jun. 2015.

MASCARENHAS, M.D.M. et al. Violência contra a pessoa idosa: análise das notificações realizadas no setor saúde - Brasil. Ciência \& Saúde Coletiva, v.17,n.9, p.2331-2341, jul.2012.

OLIVEIRA, M.L.C. et al. Características dos idosos vítimas de violência doméstica no Distrito Federal. Revista Brasileira Geriatria Gerontologia, Rio de Janeiro, v.15, n.3, p.555-566, jun. 2012.

OLIVEIRA, A.A.V.; TRIGUEIRO, D.R.S.G. Maus-tratos a idosos: revisão integrativa da literatura. Revista Brasileira de Enfermagem, Brasília, v. 66, n.1, p.128-33, jan./fev. 2013

OLIVEIRA, B.S.; DIAS, V.F.; REIS, L.A. Relação entre capacidade funcional e sinais de violência e maus tratos em idosos longevos. Fisioterapia Brasil, Vitória da Conquista, v.16, n.1, p. 32-37, jun. 2015. 
PAIVA, M.M.; TAVARES, D.M.S. Violência física e psicológica contra idosos: prevalência e fatores associados. Revista Brasileira de Enfermagem, Uberaba, v. 68, n.6, p.1035-41, nov./dez. 2015.

PARAÍBA, P. M. F.; SILVA, M. C. M. Perfil da violência contra a pessoa idosa na cidade do Recife-PE. Revista Brasileira de Geriatria e Gerontologia, Rio de Janeiro, v.18, n.2, p.295306, jan./mar. 2015.

RAMOS, F. S. Os agressores de pessoas idosas, p. 58. Dissertação para Mestrado em Educação para a Saúde, Universidade do Porto, 2011.

SILVA, E. A.; FRANÇA, L.H.F.P. Violência contra idosos na cidade do Rio de Janeiro. Estudos e Pesquisas em Psicologia, Rio de Janeiro, v. 15, n. 1, p. 155-177, fev./jun. 2015.

SILVA, C. F. S.; DIAS, C. M. S. B. Violência contra idosos: perfil sociodemográfico dos familiares agressores, tipos de violência impetrada e motivações para sua ocorrência. Revista Eletrônica Gestão e Saúde, Brasília, v.07, n. 02, p. 563-81, abr. 2016.

SANTANA, I. O.; VASCONSELOS, D. C.; COUTINHO, M. P. L. Prevalência da violência contra o idoso no Brasil: revisão analítica. Arquivos Brasileiros de Psicologia, Rio de Janeiro, v.68, n.1, p. 00-00, abr. 2016.

VERAS, R.P. A prevenção de doenças em idosos: equívocos dos atuais modelos. Caderno de Saúde Pública, Rio de Janeiro, v. 28, n.10, p.1834-1840, out. 2012.

ZANCAN, N.; WASSERMANN, V.; LIMA, G. Q. A violência doméstica a partir do discurso de mulheres agredidas. Pensando famílias, v. 17, n. 1, p. 63-76, 2013.

\section{Como citar este artigo (Formato ABNT):}

SILVA, Adriene R.; SAMPAIO, Lucas S.; REIS, Luciana A. dos; SAMPAIO, Talita S. O. Violência Contra Idosos: Associação Entre o Gênero dos Agressores e o Tipo de Violência. Id on Line Revista Multidisciplinar e de Psicologia, 2017, vol.11, n.38, p.701-712. ISSN: 1981-1179.

Recebido: 07.11.2017

Aceito: 08.11.2017 